Original Research Paper

\title{
Confirmation of Personality Types Using Visual Evoked Potential with User Interface Design Stimulus
}

\author{
${ }^{1,2}$ Ilham Perdana, ${ }^{1}$ Paulus Insap Santosa, ${ }^{1}$ Noor Akhmad Setiawan and ${ }^{3}$ Supra Wimbarti \\ ${ }^{1}$ Department of Electrical Engineering and Information Technology, Universitas Gadjah Mada, Yogyakarta, Indonesia \\ ${ }^{2}$ School of Industry Engineering, Telkom University, Bandung, Indonesia \\ ${ }^{3}$ Faculty of Psychology, Universitas Gadjah Mada, Yogyakarta, Indonesia
}

\author{
Article history \\ Received: 16-04-2021 \\ Revised: 19-10-2021 \\ Accepted: 24-10-2021 \\ Corresponding Author: \\ Ilham Perdana \\ School of Industry Engineering, \\ Telkom University, Bandung, \\ Indonesia \\ Email: ilhamp@telkomuniversity.ac.id
}

\begin{abstract}
After obtaining the consistency of Visual Evoked Potential (VEP) by using a stimulus with data-entry user interface design. This study tries to confirm whether an individual's VEP will be classified according to personality type, which results from the proceeds of conventional personality tests usually carried out by the organization that is the place of this research. The results of this study will be an attempt to complement the needs of particular organizations for the elicitation stage to show user personas by using personality types as something to consider in software development in organizations. The recording of 20 participants whose personality types were known from the results of personality tests at the organization was completed. Each individual has a unique VEP. to confirm personality types and it is necessary to prove the similarity of VEP between individuals of the same type. $93.75 \%$ of VEP is classified according to personality type. Therefore it is necessary to consider that personality type can be used as user persona for user classification at the stage of user needs. To identify personality types at the personality test stage, it is still necessary to add more participants involved to get more convincing results.
\end{abstract}

Keywords: Personality Type, User Interface Design, Visual Evoked Potential

\section{Introduction}

Personality tests attempt to verify test proceeds with the repeat test process for approving personality types into specific classes. As well as Myers-Briggs Type Indicator Instrument (MBTI) divided into 16 types, Five-Factor Model or known by other names Big Five (FFM) into five types, Sixteen Personality Factor Questionnaire (PF16) into 16 types and the Eysenck Model only divided into three classes (Schultz and Schultz, 2009). An attempt involving 160 to answer the questionnaire was given to decide the performance of the MBTI to foresee personality type and the proceeds show the degree of reliability with a performance of about 0.815 (Furnham, 1996). Research involving 133 participants completed the questionnaire to examinee predictive capability based of FFM on students be discovered to increase, achieve reliability minimum 0.59 and 0.79 for maximum (Kappe and van der Flier, 2010). Afterward, by paying attention to the characters of honesty, thoroughness and humility, a hundred and fifty respondents were carried out the personality test using the Eysenck Model. Participants were requested to answer the questionnaire to reach between 0.72 and 0.89 reliability. The research used $16 \mathrm{PF}$ to examine and contrast personality types between female and male undergraduates registered at liberal arts and business colleges, implicating 293 respondents by completing the questionnaire and the proceeds obtaining reliability minimum at 0.69 and 0.89 for maximum (Noël et al., 2016).

They have confirmed the personality types based on the proceeds of the personality test with facial recognition focused on facial expressions in thirty individuals involved distinguished with MBTI personality type, which achieved an accuracy rate at $79 \%$ for predictive (Chin et al., 2013). Other research has predicted that fifty participants involved who are distinguished based on FFM achieve 75 percent prediction accuracy (Gavrilescu, 2015). The following study verified that facial expressions on videos implicated 442 participants and achieved accuracy at minimum 5 and $83.5 \%$ for maximum (Teijeiro-Mosquera et al., 2014). Another investigation foresees facial expressions showing emotion implicated 64 participants using $16 \mathrm{PF}$ reached validity for predictive at $80 \%$ (Gavrilescu and Vizireanu, 2017). Another research carried out 186 datasets used in facial expressions reached a prediction accuracy minimum at 53.37 
and maximum at $82.02 \%$ with twenty different classes involved (Zhang et al., 2017). Kind of personality types: Melancholic, choleric, apathetic and optimistic used, involving 40 participants, the optimum prediction accuracy reached $70 \%$ by four defined types used (Setyadi et al., 2015).

This study describes the feasibility by using Visual Evoked Potential data, individual responses to organizational software user interface designs to ensure individual personality types are following the research plan that has been made (Perdana et al., 2021).

\section{Study Literature}

Human personality is the visual aspect of an individual's tends and character to have an enduring nature; therefore, personality is predictable and incline stable. Personality tests attempt to foresee the individual type of several classes (Schultz and Schultz, 2009). The study indicates that personality tests achieve a maximum success rate for predictive at $22 \%$ to find the person who has the performance intended for the organization (Martin, 2014).

Constraints for the success of personality tests include Eysenck Model, FFM, 16PF and MBTI (Fatahi et al., 2016) because the execution test process with a questionnaire have issues around thoughtful and honest respondent involvement are constantly significant and are often related to the causes of measurement errors (Gideon, 2012) by the test using a questionnaire, the organization's concerns about prospective workers or respondents pretended when a personality test was carried out during the selection process, namely with the risk of the possibility of participants lying when the personality test was running(Patterson et al., 2016). This condition can affect the organization's decisions accuracy to hire (O'Neill et al., 2017).

The questionnaires are frequently employed for software development, mainly for constructing Human-Computer Interaction (HCI) design. For example, an investigation exploring the full range of icons for mobile phones experienced for users, including the icons available on the operating system (Ghayas et al., 2019). Using a questionnaire that implicated users so that much motivation in users can be seen, the personality section will affect user satisfaction employ software (Santosa, 2009), (Santosa et al., 2005). One way to find out satisfaction in HCI development is to use a questionnaire at the elicitation stage to explore user needs and the testing stage to determine the acceptable level of the HCI design. The validity test for the acceptance stage is usually a combination of no less than two techniques for the elicitation stage to obtain valid information and it is necessary because if only just one technique, for example, using a questionnaire, it will worry that the proceeds were not reached an excellent satisfactory level (Zowghi and Coulin, 2005).
Electroencephalogram (EEG) is the transcription of an electrical for brain activity, described as voltage fluctuations generating from ionic currents in the neuronal brain (Niedermeyer and Silva, 2005). Researches with EEG used for biometric aims are increasing in use for personal recognition purpose (Alariki et al., 2018). User interface development made use of EEG has been developed to validate design acceptance (Bang et al., 2011). P300 as brain wave reader devices are effective and efficient increasingly for use for HCI development because from brain waves, using that can know the user's reaction immediately for to a design of user interface (Zickler et al., 2013) and more specific for Brain-Computer Interaction (BCI) (Wasim et al., 2018), (Fira et al., 2018). Human personality is associated with visual design style; the suitability of the design with the visual design requirements to be examined by arranging the position of an object at the display (Ziemkiewicz et al., 2012). Many study topics on EEG for personality will remain an exciting domain for research (Dickter and Kieffaber, 2014). As stated by Celikel (Jordan, 2011), personality type is contemplated in people's brains.

\section{Methods}

The steps that need to be taken in research aim to confirm the personality type by the stimulated VEP with the general form of user interface design in the form of data entry forms.

\section{Experiment Scenario}

The protocol was used to obtain EEG data, namely as a target stimulus and interspersed with non-target display stimuli in the form of a dark black screen. The stimulus is in the form of a general form of data-entry user interface design from observations of 32 different interface designs from the application display used by employees in the organization where this research is carried out.

Displayed on the LCD monitor, as shown in Fig. 1. each image is displayed represents a stimulus lasting 250 milliseconds and is followed by a black screen of 450 milliseconds. Each stimulus form was presented alternately with a dark display 100 times, resulting in a total acquisition time of $1 \mathrm{~min}$ and $10 \mathrm{sec}$ for each session. In comparison, the appearance of each stimulus produces a VEP.

\section{Eeg Recording}

The Electroencephalogram (EEG) is a mensuration for electrical activity in the brain, which is a non-invasive test. Electrodes are placed in specific positions on the scalp. Common point positions and nomenclature are defined, as can be seen in Fig. 2. Early EEG devices used wet electrodes and entire systems usually cost thousands of dollars. The latest devices, intended for use by the general public, have become available in stores at relatively low prices in recent years. 


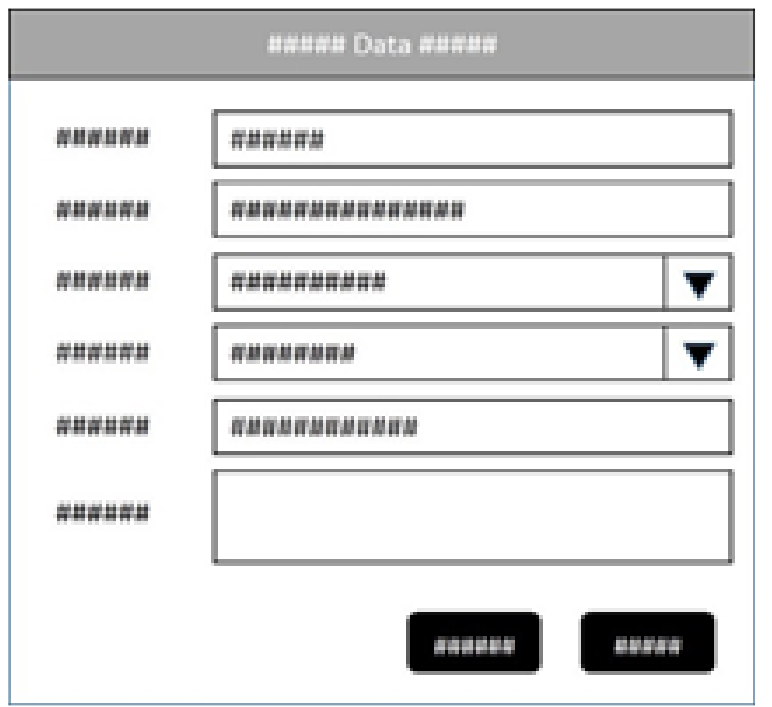

Fig. 1: Stimulus proposal

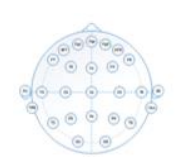

(a)

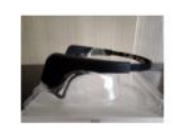

(b)

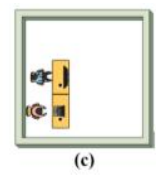

Fig. 2: (a) 10-20 international system (b) muse (c) data collection scenario

This device uses dry electrodes and sends signals wirelessly, making it more comfortable and easier to wear. This experiment used the EEG recorder, namely Muse, an end-user device and an EEG recorder. This tool is designed to be used as a headband. Available in seven EEG sensors adequate for reading data with four channels. This equipment produces a bipolar reading using FPZ (middle forehead) as a reference for TP10 (right ear), Fp2 (right forehead), FP1 (left forehead) and TP9 (left ear). A pair of DRL sensors were used for active noise-canceling reference feedback. EEG signal goes up and down and gives a sampling rate is $220 \mathrm{~Hz}$. Muse is also be equipped with a 3 -axis accelerometer to measure movement input, especially head movement. This device uses a lithium-ion rechargeable battery and for data communication uses Bluetooth. The developed software is available for raw data recording and real-time visualization, including additional information signals available for hereafter analysis.

Fig.2b. Shows the Muse EEG recording device and Fig. 2c. Illustrated for design scenario of data collection from participants.

\section{Pre-Processing}

This step is to get data declared as valid sample data and signal averaging from each voltage sample as long as the stimulus is raised to eliminate noise. Each session will look for the one that best represents the response to the stimulus using Pearson correlation. Based on the correlation coefficient value, the calculation results are sought for the sample data that has the most correlation values between \pm 0.8 and \pm 1 (very strong), between \pm 0.5 and \pm 0.79 (strong) and between \pm 0.3 and \pm 0.49 (medium) so that it is stated as a representative sample is valid.

\section{Feature Extraction}

This step is to see valid VEP data by testing the permanent nature by comparing valid sample data for each session per participant as valid sample data representing VEP from each participant if, after being tested, it has a coefficient value exceeding 0.5 (strong-very strong).

\section{Classification}

This step is to see if the VEP between participants has similarities based on the participant's personality type. It is testing the ability to confirm personality type, the classification process using Spearman Correlation. The first step is to determine the golden standard for each personality type by selecting the sample with the best correlation value that shows the permanent nature of the four recording sessions of each participant. Then the next step is to test whether it can be done consistently to confirm the VEP of other participants using the Spearman correlation.

\section{Results and Discussion}

\section{The Pattern of VEP against Defined Stimulus}

Each participant was recorded at least four times with an interval of at least one week between recording sessions to determine the extent of the permanent level of VEP that appeared. The results showed that permanent traits consistently appeared in the FP1 channel while only a small percentage of permanent traits were found in all channels in each individual. The test results are permanent per channel, so only the VEP on channel FP1 is used for the next stage. EEG data recording of 20 participants has been carried out based on their permanent level, shown in Table 1. Then the Best VEP for each personality type, known as the golden standard for each type (Ranking 1-4), is shown in Fig. 3.

\section{Testing the Ability to Confirm Personality Type}

After determining the golden standard for each personality type, the next step is to test whether it can be done consistently to confirm the VEP of other participants using the Spearman correlation.

Figure 4 to 6 are a collection of VEPs from 16 participants (ranking 5-20) who have been recorded and identified personality types in order based on their level of permanence to test the extent to which they can confirm the personality types based on the VEP which will be compared with the existing golden standard. 
The VEP pattern in each participant can be seen with the naked eye, for type $S$ tends to be flat at the beginning then rises, type I tends to be flat at the beginning and then decreases, type $\mathrm{C}$ has an ascending zigzag pattern. Dan type $\mathrm{D}$ has an ascending pattern.

The trial to confirm the similarity of the FEP pattern of sixteen participants was measured one by one compared to the VEP of four participants who had the best level of permanence for each personality type. The comparison uses a comparison based on the Spearman correlation value.

The correlations are shown in Table 2. Each personality type has the highest correlation value, which is expressed as an approximate personality type indicating that this type has similarities using the Spearman correlation method. The highest correlation value was determined by comparing VEP participants with the gold standard (P1-P4). For example, P5 has a correlation value of 0.87 (P1), -0.82 (P2), 0.24 (P3) and 0.82 (P4), then the highest correlation value is 0.87 , so P5 shows similarities to P1 (S personality type). After carrying out the iteration process sixteen times, the

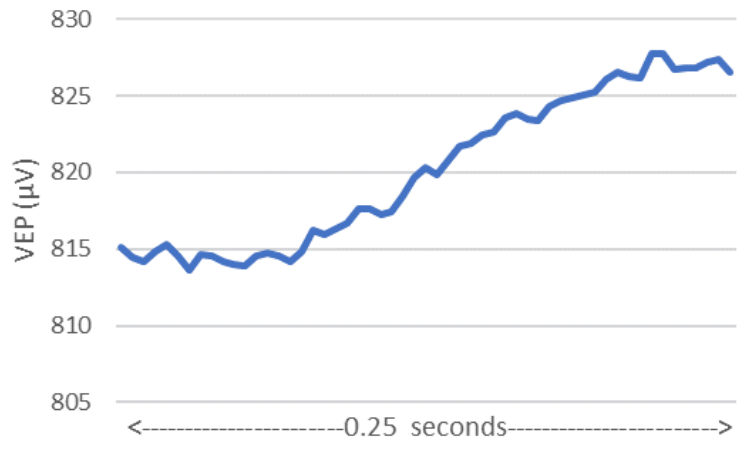

(a)

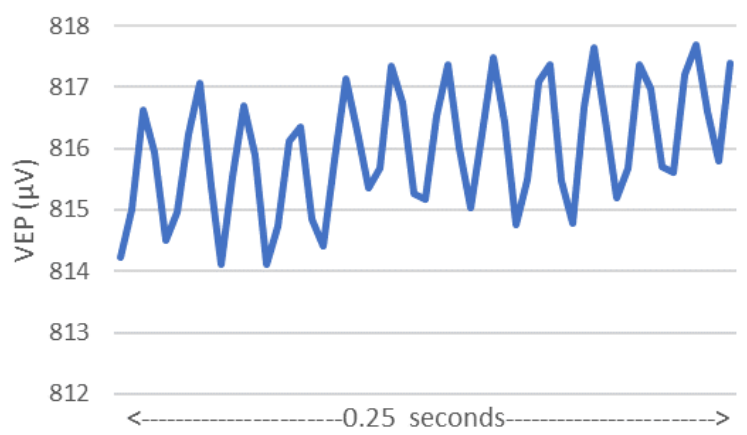

(c) results of the recapitulation of the confirmation process are obtained, as shown in Table 3. Figure 7 represents the results of the classification.

Noting that each stage has been carried out, a stimulus form in the form of a user interface design has been generated, resulting from a generalization of the interface design form. The stimulus is used and then the participant's response is recorded from the brain waves of each participant involved due to a visual stimulus called VEP.

The VEP recorded on channel FP1 shows the best permanent properties at a correlation value of 0.54 to 0.99. Based on the best permanent level, the best VEP for each participant is then determined to test the extent to which the confirmation of personality type is consistent with the recorded VEP.

The best VEP's from representatives of each personality type is called the golden standard. The next step is to test the level of similarity of other participants' VEP by paying attention to the correlation value using the Spearman correlation method between participants' VEP. Then compared one by one with the golden standard, the results were classified as $93.75 \%$.

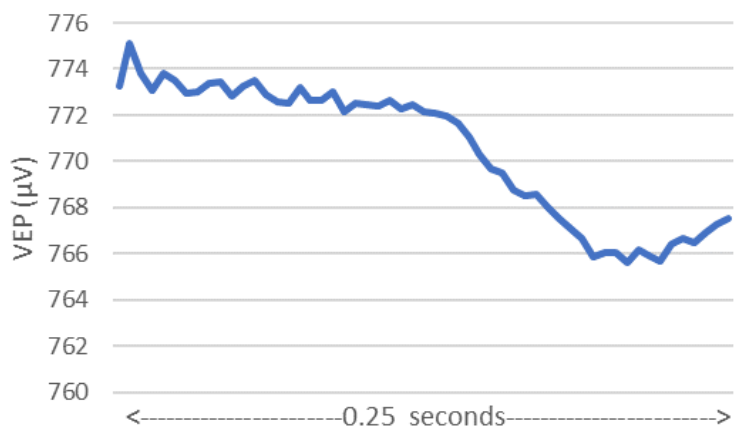

(b)

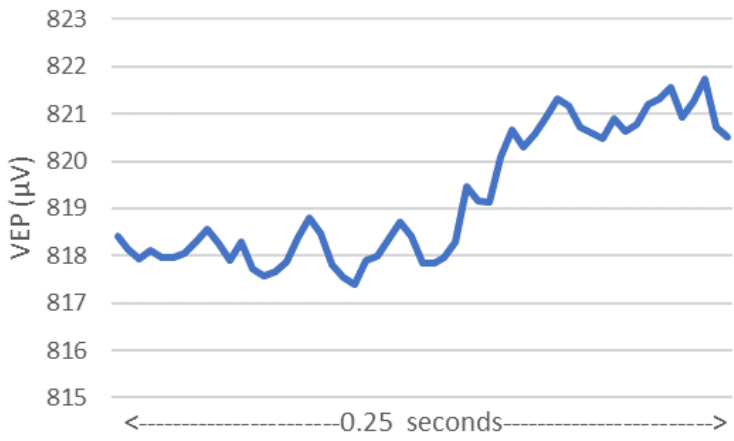

(d)

Fig. 3: Visual Evoked Potential (a) P1 (b) P2 (c) P3 (d) P4 
Ilham Perdana et al. / Journal of Computer Science 2021, 17 (11): 1138.1146 DOI: $10.3844 /$ jessp.2021.1138.1146

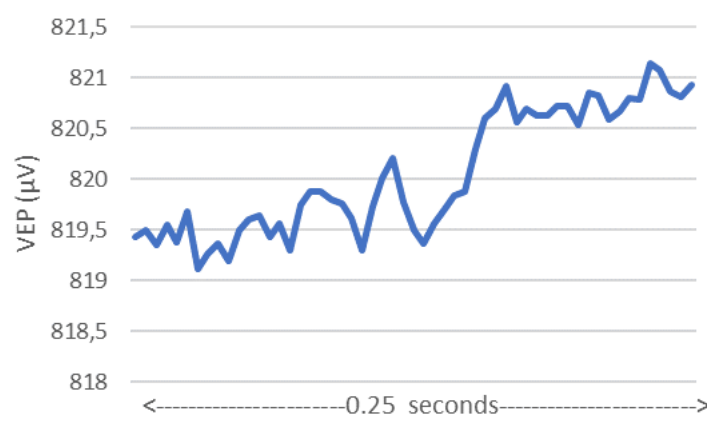

(a)

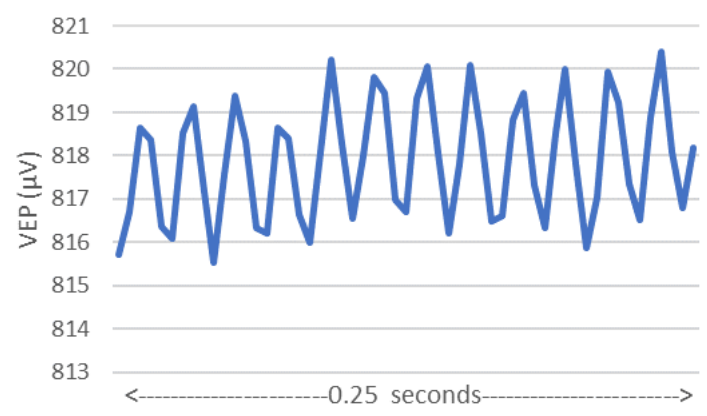

(c)

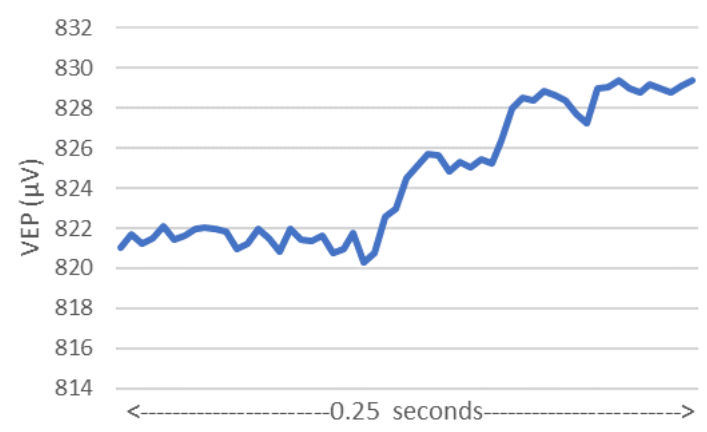

(e)

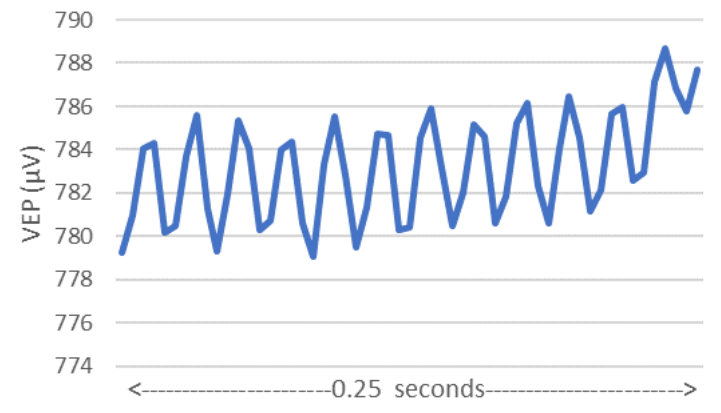

(b)

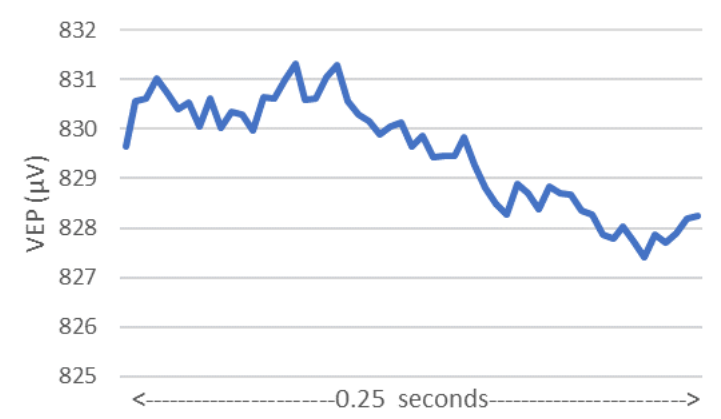

(d)

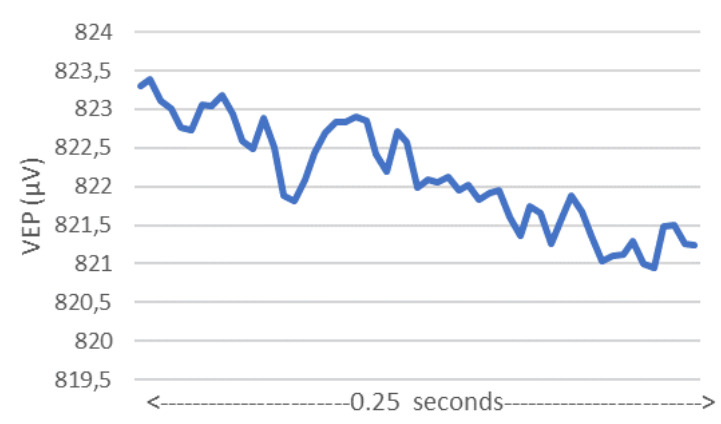

(f)

Fig. 4: Visual Evoked Potential (a) P5 (b) P6 (c) P7 (d) P8 (e) P9 (f) P10

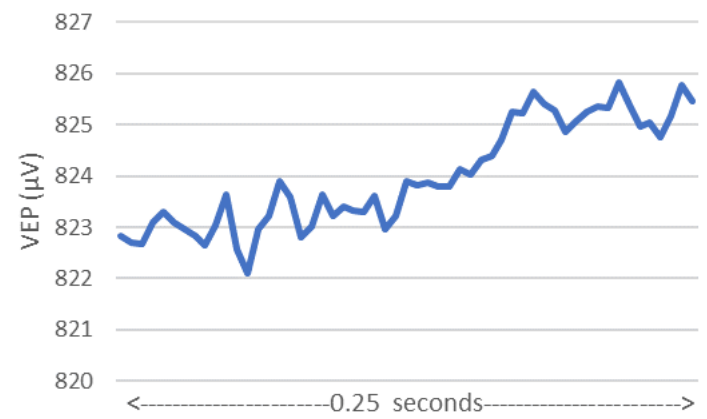

(a)

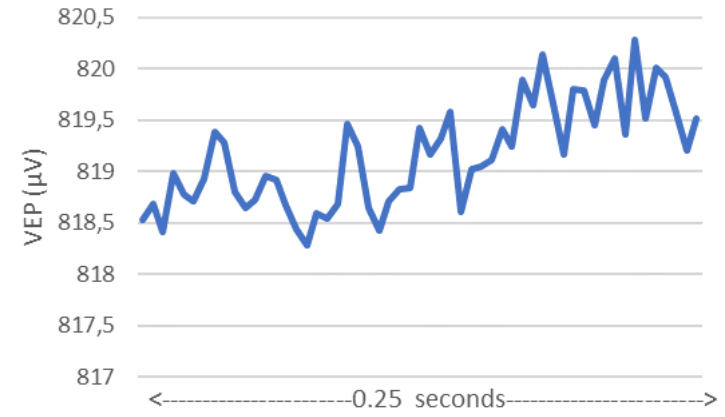

(b) 


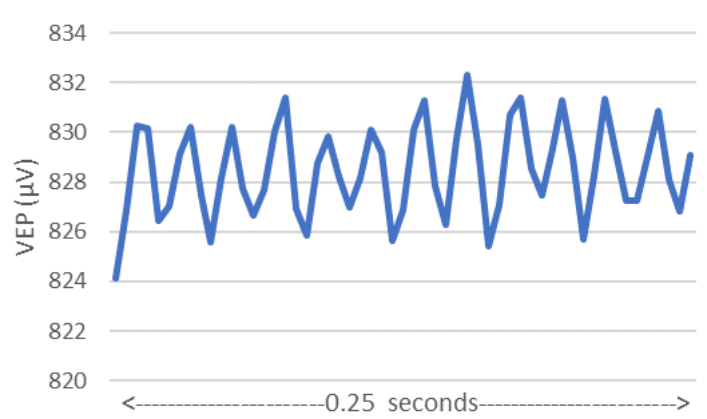

(c)

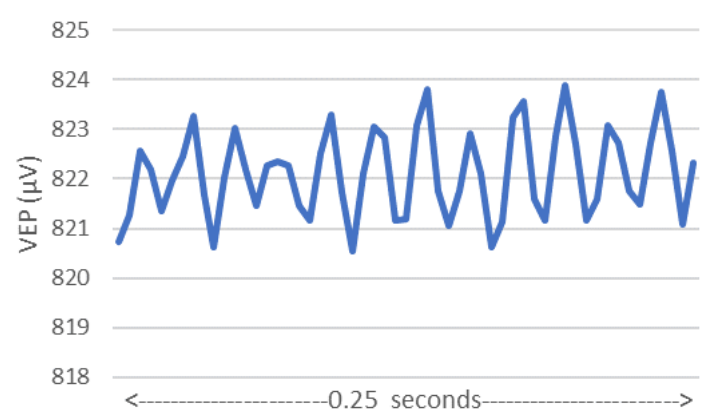

(e)

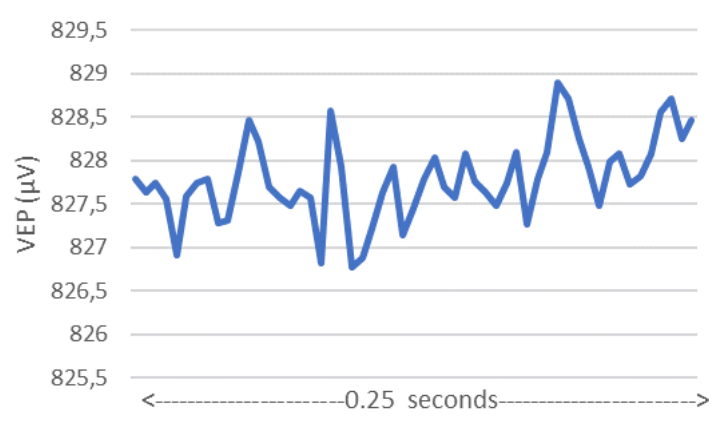

(g)

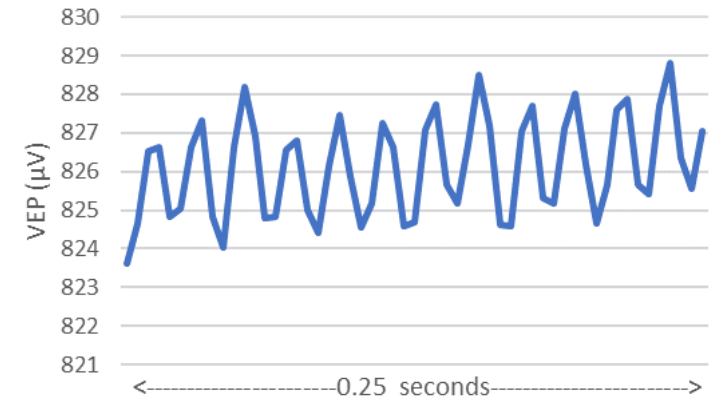

(d)

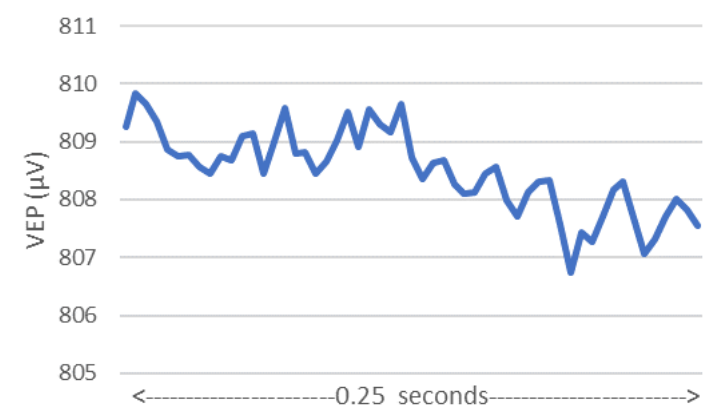

(f)

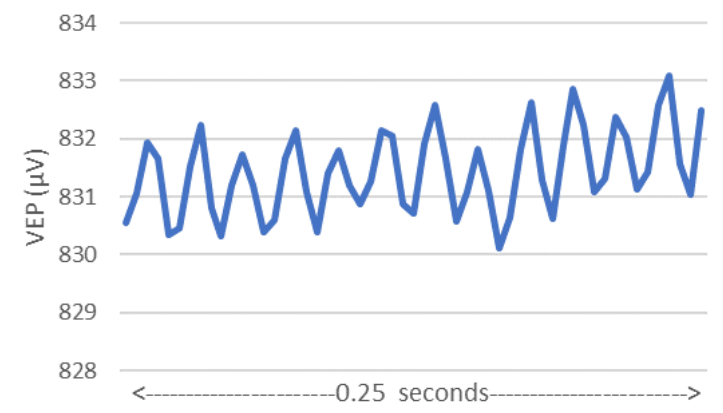

(h)

Fig. 5: Visual evoked potential (a) P11 (b) P12 (c) P13 (d) P14 (e) P15 (f) P16 (g) P17 (h) P18

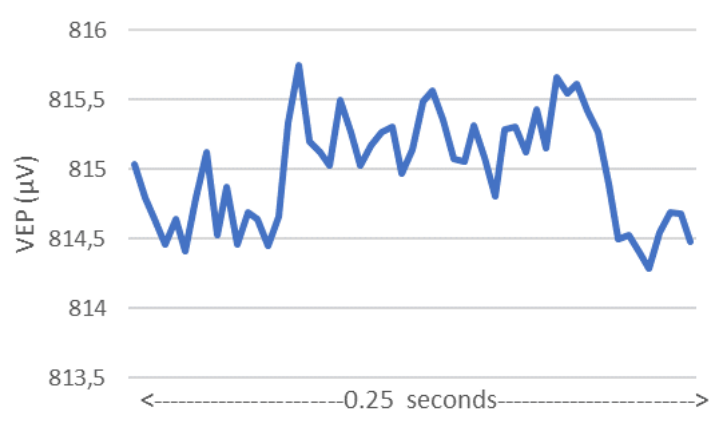

(a)

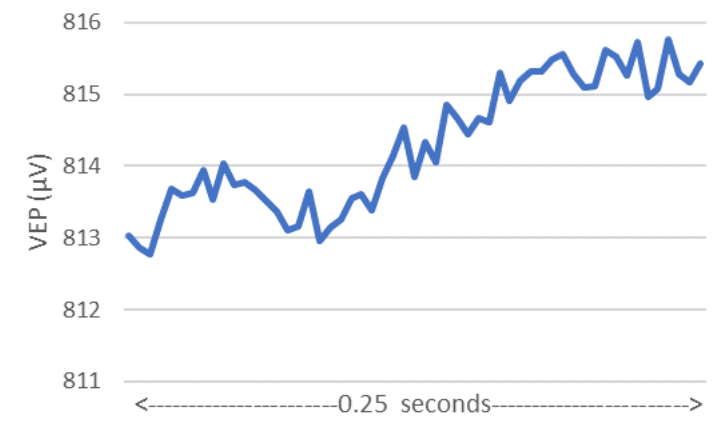

(b)

Fig. 6: Visual evoked potential (a) P19 (b) P20 
Ilham Perdana et al. / Journal of Computer Science 2021, 17 (11): 1138.1146 DOI: 10.3844/jessp.2021.1138.1146

Table 1: Correlation values inter-datasets on the best recording of each participant

\begin{tabular}{llll}
\hline Ranking & Participant code & Personality type & Correlation value \\
\hline 1 & P1 (S01) & S & 0.99 \\
2 & P2 (I04) & I & 0.99 \\
3 & P3 (C07) & C & 0.94 \\
4 & P4 (D01) & D & 0.91 \\
5 & P5 (D02) & D & 0.90 \\
6 & P6 (C02) & C & 0.90 \\
7 & P7 (C08) & I & 0.90 \\
8 & P8(I03) & S & 0.89 \\
9 & P9(S03) & I & 0.89 \\
10 & P10(I01) & S & 0.86 \\
11 & P11(S04) & C & 0.86 \\
12 & P12(S05) & C & 0.82 \\
13 & P13(C04) & C & 0.82 \\
14 & P14(C06) & I & 0.80 \\
15 & P15(C03) & C & 0.67 \\
16 & P16(I02) & C & 0.66 \\
18 & P17(C01) & C & 0.63 \\
19 & P18(C05) & S & 0.60 \\
\hline
\end{tabular}

Table 2: Comparison of the similarity level of VEP patterns between participants using the spearman correlation

\begin{tabular}{lllll}
\hline Participant code & P1 & P2 & P3 & P4 \\
\hline P5 & $0.87^{*}$ & -0.82 & 0.24 & 0.82 \\
P6 & 0.40 & -0.41 & $0.86^{*}$ & 0.32 \\
P7 & 0.13 & -0.18 & $0.88^{*}$ & 0.04 \\
P8 & -0.87 & $0.85^{*}$ & -0.20 & -0.82 \\
P9 & $0.85^{*}$ & -0.85 & 0.30 & 0.81 \\
P10 & -0.85 & $0.89^{*}$ & -0.23 & -0.73 \\
P11 & $0.87^{*}$ & -0.83 & 0.27 & 0.80 \\
P12 & $0.88^{*}$ & -0.89 & 0.23 & 0.71 \\
P13 & 0.07 & -0.17 & $0.87^{*}$ & 0.06 \\
P14 & 0.23 & -0.28 & $0.89^{*}$ & 0.17 \\
P15 & 0.09 & -0.17 & $0.83^{*}$ & 0.03 \\
P16 & -0.87 & $0.81^{*}$ & -0.20 & -0.73 \\
P17 & 0.40 & -0.41 & $0.43^{*}$ & 0.37 \\
P18 & 0.29 & -0.35 & $0.83^{*}$ & 0.23 \\
P19 & -0.22 & $0.23^{*}$ & -0.01 \\
P20 & 0.10 & -0.75 & 0.39 & 0.61 \\
\hline
\end{tabular}

*Highest correlation value per row

Table 3: Method performance in confirming personality type

\begin{tabular}{ll}
\hline Participant code & Correctness* \\
\hline P5 & 0 \\
P6 & 1 \\
P7 & 1 \\
P8 & 1 \\
P9 & 1 \\
P10 & 1 \\
P11 & 1 \\
P12 & 1 \\
P13 & 1 \\
P14 & 1 \\
P15 & 1 \\
P16 & 1 \\
P17 & 1 \\
P18 & 1 \\
P19 & 1 \\
P20 & 1 \\
$*(0=$ False, $1=$ True $)$ & 1 \\
\end{tabular}

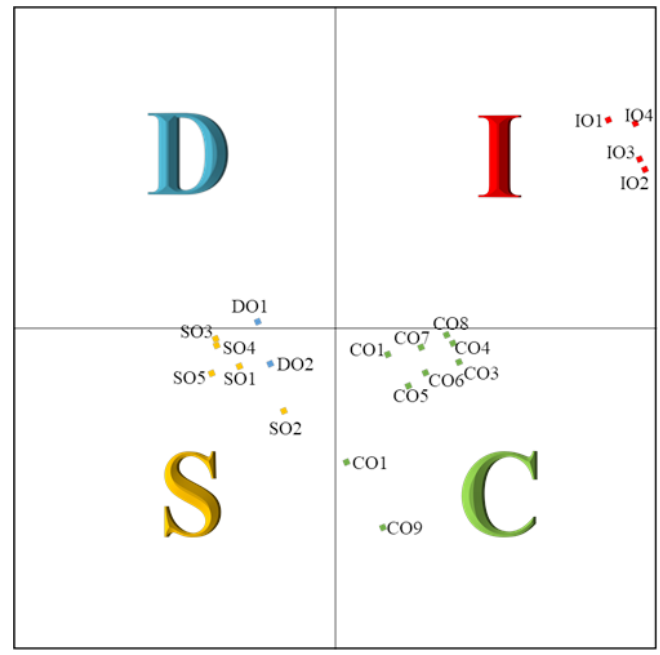

Fig. 7: Classification of VEP based on personality type 


\section{Conclusion}

In this experiment, it was found that there is a similar pattern of VEP between individuals who have the same personality type. Confirmation results using Spearman correlation have a relatively high accuracy of 93.75 percent.

Classification results based on VEP relevant to personality types can be used as an alternative method to confirm personality types for the classification needs of prospective users who will be involved in the user requirements stage in the development of information systems in particular or work support software general. Meanwhile, the need for personality tests needs to be investigated further by increasing the number of participants involved to get higher confidence to be proposed as an alternative personality test method.

\section{Acknowledgment}

This research was supported by The Indonesia Endowment Fund for Education (Lembaga Pengelola Dana Pendidikan/LPDP).

\section{Funding Information}

This research is funded by The Indonesia Endowment Fund for Education (Lembaga Pengelola Dana Pendidikan/LPDP).

\section{Author's Contributions}

Ilham Perdana: Reviewed the pre-processing phase, organized the entire survey and contributed to writing the manuscript.

Paulus Insap Santosa, Supra Wimbarti and Noor Akhmad Setiawan: Idea formation and research supervision.

\section{Ethics}

This article is original and contains unpublished material. The corresponding author confirms that all other authors have read and approved the manuscript and no ethical issues are involved.

\section{References}

Alariki, A. A., Ibrahimi, A. W., Wardak, M., \& Wall, J. (2018). A review study of brian activity-based biometric authentication. Journal of Computer Science, 14(2), 173-181. doi.org/10.3844/jcssp.2018.173.181

Bang, J. W., Lee, E. C., \& Park, K. R. (2011). New computer interface combining gaze tracking and brainwave measurements. IEEE Transactions on Consumer Electronics, 57(4), 1646-1651. doi.org/10.1109/TCE.2011.6131137
Chin, S., Lee, C. Y., \& Lee, J. (2013). An automatic method for motion capture-based exaggeration of facial expressions with personality types. Virtual Reality, 17(3), 219-237. doi.org/10.1007/s10055-013-0227-8

Dickter, C. L., \& Kieffaber, P. D. (2014). EEG Methods for the Psychological Sciences.

Fatahi, S., Moradi, H., \& Kashani-Vahid, L. (2016). A survey of personality and learning styles models applied in virtual environments with emphasis on e-learning environments. Artificial Intelligence Review, 46(3), 413-429. doi.org/10.1007/s10462-016-9469-7

Fira, M., Goras, L., \& Lazar, A. (2018). On P300 detection using scalar products. International Journal of Advanced Computer Science and Applications, 9(1). doi.org/10.14569/IJACSA.2018.090113

Furnham, A. (1996). The big five versus the big four: The relationship between the Myers-Briggs Type Indicator (MBTI) and NEO-PI five factor model of personality. Personality and individual differences, 21(2), 303-307. doi.org/10.1016/0191-8869(96)00033-5

Gavrilescu, M. (2015, November). Study on determining the Big-Five personality traits of an individual based on facial expressions. In 2015 E-Health and Bioengineering Conference (EHB) (pp. 1-6). IEEE. doi.org/10.1109/EHB.2015.7391604

Gavrilescu, M., \& Vizireanu, N. (2017). Predicting the Sixteen Personality Factors (16PF) of an individual by analyzing facial features. EURASIP Journal on Image and Video Processing, 2017(1), 1-19. doi.org/10.1186/s13640-017-0211-4

Ghayas, S., Al-Hajri, S. A., \& Sulaiman, S. (2019). Experimental study: The effects of mobile phone icons characteristics on users' age groups. Journal of Computer Science, 14(8), 1134-1143.

Gideon, L. (Ed.). (2012). Handbook of survey methodology for the social sciences. New York: Springer. doi.org/10.1007/978-1-4614-3876-2

Jordan, M. E. (Ed.). (2011). Personality traits: Theory, testing and influences. Nova Science Publisher's, Incorporated.

Kappe, R., \& van der Flier, H. (2010). Using multiple and specific criteria to assess the predictive validity of the Big Five personality factors on academic performance. Journal of Research in Personality, 44(1), 142-145. doi.org/10.1016/j.jrp.2009.11.002

Martin, W. (2014). The problem with using personality tests for hiring. Harvard Business Review, 27. https://www.consultproactive.com/wpcontent/uploads/2021/04/HBR_Article.pdf 
Niedermeyer, E., \& Silva, F. L. da. (2005). Electroencephalography. Lippincott Williams \& Wilkins.

Noël, N. M., Trocchia, P., \& Luckett, M. (2016). A predictive psychometric model to identify personality and gender differences of college majors. The International Journal of Management Education, 14(3), 240-247. doi.org/10.1016/j.ijme.2016.05.004

O'Neill, T. A., Lewis, R. J., Law, S. J., Larson, N., Hancock, S., Radan, J., ... \& Carswell, J. J. (2017). Forced-choice pre-employment personality assessment: Construct validity and resistance to faking. Personality and Individual Differences, 115, 120-127. doi.org/10.1016/j.paid.2016.03.075

Patterson, F., Knight, A., Dowell, J., Nicholson, S., Cousans, F., \& Cleland, J. (2016). How effective are selection methods in medical education? A systematic review. Medical education, 50(1), 36-60. doi.org/10.1111/medu.12817

Perdana, I., Insap, P., Akhmad, N., \& Wimbarti, S. (2021). Confirmation of Personality Types Using Visual Evoked Potential with User Interface Design Stimulus - A Research Plan. Turkish Online Journal of Qualitative Inquiry, 12(9), 4130-4138. https://www.tojqi.net/index.php/journal/article/view/ 6428

Santosa, P. I. (2009). Usability of e-learning portal and how it affects students'attitude and satisfaction, an exploratory study. Pacis 2009 Proceedings, 71. https://aisel.aisnet.org/cgi/viewcontent.cgi?article=1 070\&context $=$ pacis 2009

Santosa, P. I., Wei, K. K., \& Chan, H. C. (2005). User involvement and user satisfaction with information-seeking activity. European Journal of Information Systems, 14(4), 361-370.

https://link.springer.com/article/10.1057/palgrave.eji s.3000545

Schultz, D. P., \& Schultz, S. E. (2009). Theories of Personality, Ninth Edition. In American Sociological Review. Michele Sordi Assistant. doi.org/10.2307/2089174
Setyadi, A. D., Harsono, T., \& Wasista, S. (2015, September). Human character recognition application based on facial feature using face detection. In 2015 International Electronics Symposium (IES) (pp. 263-267). IEEE. doi.org/10.1109/ELECSYM.2015.7380852

Teijeiro-Mosquera, L., Biel, J. I., Alba-Castro, J. L., \& Gatica-Perez, D. (2014). What your face vlogs about: Expressions of emotion and big-five traits impressions in YouTube. IEEE Transactions on Affective Computing, 6(2), 193-205. doi.org/10.1109/TAFFC.2014.2370044

Wasim, M., Sajjad, M., Ramzan, F., Khan, U. G., \& Mahmood, W. (2018). A Review and Classification of Widely used Offline Brain Datasets. International journal of advanced computer science and applications, 9(2), 399-408. doi.org/10.14569/IJACSA.2018.090254

Zhang, T., Qin, R. Z., Dong, Q. L., Gao, W., Xu, H. R., \& Hu, Z. Y. (2017). Physiognomy: Personality traits prediction by learning. International Journal of Automation and Computing, 14(4), 386-395. doi.org/10.1007/s11633-017-1085-8

Zickler, C., Halder, S., Kleih, S. C., Herbert, C., \& Kübler, A. (2013). Brain painting: Usability testing according to the user-centered design in end users with severe motor paralysis. Artificial intelligence in medicine, 59(2), 99-110. doi.org/10.1016/j.artmed.2013.08.003

Ziemkiewicz, C., Ottley, A., Crouser, R. J., Yauilla, A. R., Su, S. L., Ribarsky, W., \& Chang, R. (2012). How visualization layout relates to locus of control and other personality factors. IEEE transactions on visualization and computer graphics, 19(7), 1109-1121. doi.org/10.1109/TVCG.2012.180

Zowghi, D., \& Coulin, C. (2005). Requirements elicitation: A survey of techniques, approaches and tools. In Engineering and managing software requirements (pp. 19-46). Springer, Berlin, Heidelberg. doi.org/10.1007/3-540-28244-0_2 